\title{
Acoustical studies on binary liquid mixtures of some 1,3,4-oxadiazole derivatives with acetone at $303.15 \mathrm{~K}$
}

\author{
G. Alamelumangai, N. Santhi* \\ Department of Chemistry, Government Arts College, C. Mutlur, Chidambaram, Tamil Nadu, India \\ *E-mail address: nsaanthi@gmail.com
}

\begin{abstract}
The wide spread use of 1,3,4-oxadiazoles as a scaffold in medicinal chemistry establishes this moiety as an important bioactive class of heterocycles. In the present study ultrasonic velocity $(u)$, density $(\rho)$ and viscosity $(\eta)$ have been measured at frequency $2 \mathrm{MHz}$ in the binary mixtures of $1,3,4-$ oxadiazole derivatives in acetone at $303.15 \mathrm{~K}$ using ultrasonic interferometer technique. The measured value of ultrasonic velocity, density and viscosity have been used to estimate the acoustical parameters namely adiabatic compressibility $\left(\beta_{\mathrm{ad}}\right)$, relaxation time $(\tau)$, acoustic impedance $\left(Z_{\mathrm{i}}\right)$, free length $\left(\mathrm{L}_{\mathrm{f}}\right)$, free volume $\left(\mathrm{V}_{\mathrm{f}}\right)$ and internal pressure $\left(\pi_{\mathrm{i}}\right)$, with a view to investigate the nature and strength of molecular interactions. The obtained result support the occurrence of molecular association through hydrogen bonding in the binary liquid mixtures.
\end{abstract}

Keywords: Acoustical properties; hydrogen bonding; binary mixtures

\section{INTRODUCTION}

Ultrasonic offer the most exciting and fascinating field of scientific research among the researcher. since the ultrasonic and other related thermo acoustic parameters provide useful information regarding the structure of molecules, molecular order, molecular packing, inter and intra -molecular interaction ${ }^{1-2}$ etc. Ultrasonic study of liquid and liquid mixture has gained much importance during the last two decades in assessing the nature of molecular interaction and investigating the physiochemical behavior of system ${ }^{3-4}$.

Molecular interaction in liquid mixtures has been extensively studied using ultrasonic technique by many workers ${ }^{5}$, because mixed solvents find practical applications in many chemical, biological and industrial processes. 1,3,4-oxadiazole derivatives are heterocyclic compounds containing one oxygen and two nitrogen atoms in a five-membered ring. 1,3,4oxadiazole derivatives have played a major role in the pharmaceutical chemistry. Therefore the applications of these compounds attract us to study their behaviour in acetone.

We report here the results of study on binary liquid mixture of 1,3,4-oxadiazole derivatives over the entire range of composition at $\mathrm{T}=303.15 \mathrm{~K}$. By using the experimentally measured values of ultrasonic velocity $(\mathrm{u})$, density $(\mathrm{r})$ and viscosity $(\eta)$, various acoustical parameters like excess adiabatic compressibility, excess intermolecular free length, excess acoustic impedance, and excess ultrasonic velocity have been calculated the mixture. The 
calculated deviations and excess functions have been explained on the basis of the intermolecular interactions present in these mixtures. The binary liquid systems studied here is

(i) 1-(5-amino-2-phenyl-1,3,4-oxadiazole-3(2H)-yl) ethanone - acetone,

(ii) 1-(5-amino-2-(3-(trifluoromethyl)phenyl)-1,3,4-oxadiazole-3(2H)-yl) ethanone - acetone,

(iii) 1-(5-amino-2-(2,4-dimethoxyphenyl)-1,3,4-oxadiazole-3(2H)-yl) ethanone - acetone.

\section{EXPERIMENTAL SECTION}

The Compounds were recrystalized before use. The solvent used in the present work of AR grade and were purified according to the standard procedure described in the literature ${ }^{6}$. Solutions of different molarity were prepared for each binary system. The ultrasonic velocity in the mixture was measured using a variable path fixed frequency ultrasonic interferometer working at $2 \mathrm{MHz}$ frequency (Mittal enterprises, New Delhi). The accuracy of sound velocity was $\pm 0.1 \mathrm{~ms}^{-1}$.

The density was determined at the experimental temperature using $10 \mathrm{ml}$ capacity specific gravity bottle immersed in a thermostatic bath (accuracy $+0.01{ }^{\circ} \mathrm{C}$ ). The volume of the bottle at the experimental temperatures, viz. $303.15 \mathrm{~K}$ was ascertained using doubly distilled water. The densities of water at these temperatures were obtained from literature. The viscosity of pure liquids and liquid mixtures at $303.15 \mathrm{~K}$ were determined using an Ostwald viscometer ${ }^{30-35}$.

\section{THEORY \& CALCULATIONS}

The ultrasonic velocity, density and viscosity data described many parameters for understanding solvent interaction and structural effect. Various acoustical parameters like adiabatic compressibility $\left(\beta_{\mathrm{ad}}\right)$, intermolecular free length $\left(\mathrm{L}_{\mathrm{f}}\right)$, specific acoustical impendence $\left(Z_{\mathrm{i}}\right)$, Rao's molar sound function $(\mathrm{R})$, Vander Waals constant (b), etc., have been computed using the following standard equations ${ }^{7-19}$.

1. Adiabatic compressibility, $\beta_{a d}=1 / u^{2} \rho$

2. Intermolecular free length, $L_{f}=K / u \rho^{1 / 2}$

3. Relative association, $(R \cdot A)=\left(\frac{\rho}{\rho_{0}}\right)\left(\frac{C_{0}}{C}\right)^{1 / 3}$

4. Specific Acoustic impedance, $z_{i}=P_{e} / C$

5. Viscous relaxation time, $\tau=\frac{4}{3} \beta \eta$

6. Relaxation strength, $r=1-\left(\frac{u}{u_{\alpha}}\right)^{2}$

7. Rao's constant or molar sound velocity, $R=V u^{1 / 3}$

8. Wada's constant, $B^{\prime}=\frac{M}{\rho} K_{s}^{1 / 7}$ 
9. Ultrasonic attenuation, $\frac{\alpha}{\mathrm{f}^{2}}=\frac{8 \pi^{2} \eta}{3 \mathrm{u}^{3} \rho}$

10. Vander Waal's constant, $b=\frac{M}{\rho}\left\{1-\left(\frac{R T}{M C^{2}}\right)\left[1+\left(\frac{M C^{2}}{R T}\right)^{1 / 2}-1\right]\right\}$

11. Isothermal compressibility, $\beta_{T}=\frac{1.71 \times 10^{-3}}{T^{4 / 9} u^{1 / 2} \rho^{1 / 3}}$

12. Isothermal expansion co-efficient, $\alpha=\left(0.0191 \beta_{T}\right)^{1 / 4}$

13. Internal pressure, $\pi_{i}=\frac{\alpha T}{\beta_{T}}$

14. Free volume, $V_{f}=\left(\frac{b R T}{\pi_{i}}\right)^{3}\left(\frac{1}{V^{2}}\right)$

15. Solvation number, $S_{n}=\left(\frac{n_{1}}{n_{2}}\right)\left(1-\frac{\beta}{\beta_{0}}\right)$

\section{RESULTS AND DISCUSSION}

Tables 1 to 3 shows the measured ultrasonic velocity, density and related acoustical parameters of 1,3,4-oxadiazole derivatives with acetone at $303 \mathrm{~K}$. These measured acoustical parameters of 1,3,4-oxadiazole derivatives with acetone at $303 \mathrm{~K}$ were also shown graphically in Figure 1 to 9 . It is observed that ultrasonic velocity, density, viscosity and acoustic impedance shows nonlinear increasing variation with increase in molar concentration. This indicates the complex formation and intermolecular weak association may be due to hydrogen bond formation ${ }^{20}$. This behaviour is the result of structural changes occurring in the mixture.

Adiabatic compressibility $\left(\beta_{\mathrm{ad}}\right)$ shows an inverse behaviour compared to the ultrasonic velocity. Adiabatic compressibility nonlinearly decreases with increase in concentration of 1,3,4-oxadiazole derivatives (shown in Table 2). The decrease in compressibility implies that there is an enhanced molecular association in the system with increase in solute concentration $^{21-22}$.

The opposite trend of ultrasonic velocity and adiabatic compressibility indicate association among interacting 1,3,4-oxadiazole derivatives and acetone molecules. In the present systems, free length varies nonlinearly with increase in molar concentration suggest the significant interaction between solute and solvent due to which structural arrangement is also affected ${ }^{23}$.

Relaxation time decreases with increase in concentration. The relaxation time which is order of $10^{-12} \mathrm{sec}$ is due to structural relaxation ${ }^{24-25}$ process in such a case it is suggested that molecules get rearranged due to co-operative process ${ }^{26-27}$. 
Table 1. Velocity(u), Density ( $\rho)$, Viscosity $(\eta)$ and Molar volume (Vm) of 2,5-Disubstituted-1,3,4-Oxadiazole derivatives with Acetone at $303.15 \mathrm{~K}$.

\begin{tabular}{|c|c|c|c|c|}
\hline \multirow{2}{*}{$\begin{array}{c}\text { Mole } \\
\text { fraction }\end{array}$} & \multicolumn{5}{|c|}{$1,3,4-$ Oxadiazole derivatives } \\
\cline { 2 - 5 } & $\mathrm{u}$ & $\rho$ & $\eta \times 10^{3}$ & $\mathrm{Vm} \times 10^{6}$ \\
\hline $\mathrm{X}_{2}$ & $\mathrm{~ms}^{-1}$ & $\mathrm{kgm}^{-3}$ & $\mathrm{Nm}^{-1} \mathrm{sec}$ & $\mathrm{m}^{3} / \mathrm{mol}$ \\
\hline \multicolumn{5}{|c|}{ Compound A1 } \\
\hline 0.0063 & 1290.27 & 756.37 & 0.68 & 78.01 \\
\hline 0.0125 & 1358.20 & 770.85 & 0.71 & 77.74 \\
\hline 0.0250 & 1412.67 & 787.74 & 0.74 & 78.41 \\
\hline 0.0500 & 1433.40 & 797.65 & 0.76 & 82.04 \\
\hline 0.1000 & 1563.00 & 803.88 & 0.81 & 90.56 \\
\hline \multicolumn{5}{|c|}{ Compound A2 } \\
\hline 0.0063 & 1227.67 & 768.31 & 0.63 & 77.35 \\
\hline 0.0125 & 1296.73 & 777.20 & 0.66 & 78.20 \\
\hline 0.0250 & 1351.53 & 788.51 & 0.70 & 80.48 \\
\hline 0.0500 & 1429.47 & 795.49 & 0.74 & 86.53 \\
\hline 0.1000 & 1541.53 & 801.97 & 0.78 & 99.24 \\
\hline \multicolumn{5}{|c|}{ Compound A3 } \\
\hline 0.0063 & 1305.53 & 777.96 & 0.61 & 76.33 \\
\hline 0.0125 & 1353.60 & 780.38 & 0.65 & 77.75 \\
\hline 0.0250 & 1432.93 & 787.62 & 0.68 & 80.33 \\
\hline 0.0500 & 1495.40 & 794.98 & 0.71 & 86.10 \\
\hline 0.1000 & 1562.33 & 799.56 & 0.75 & 98.56 \\
\hline
\end{tabular}

Table 2. Adiabatic compressibility ( $\beta \mathrm{ad}$ ), intermolecular free length (Lf), Specific acoustic impedance (Zi), Rao's constant (R), Wada's constant (W), Vander waal's constant (b) and Ultrasonic attenuation $\left(\alpha / \mathrm{f}^{2}\right)$ of 2,5-Disubstituted-1,3,4-oxadiazole derivatives with Acetone at $303.15 \mathrm{~K}$.

\begin{tabular}{|c|c|c|c|c|c|c|c|}
\hline $\begin{array}{c}\text { Mole } \\
\text { fraction }\end{array}$ & $\beta \mathrm{ad} \times 10^{9}$ & $\mathrm{~L}_{\mathrm{f}} \times 10^{10}$ & $\begin{array}{c}\mathrm{Z}_{\mathrm{i}} \\
\times 10^{6}\end{array}$ & $\mathrm{R} \times 10^{6}$ & $\mathrm{~W} \times 10^{-3}$ & $\mathrm{~b} \times 10^{6}$ & $\alpha / \mathrm{f}^{2} \times 10^{-14}$ \\
\hline $\mathrm{X}_{2}$ & $\mathrm{~Pa}^{-1}$ & $\mathrm{~m}$ & $\mathrm{kgm}^{-2} \mathrm{~s}$ & $\mathrm{~m}^{10 / 3} / \mathrm{kgs}^{1 / 3} \mathrm{~mol}$ & $\left(\mathrm{~m}^{3} / \mathrm{kg} \cdot \mathrm{mol}\right)\left(\mathrm{kg} / \mathrm{ms}^{2}\right)^{-1 / 7}$ & $\mathrm{~m}^{3} / \mathrm{mol}$ & $\mathrm{sec}$ \\
\hline \multicolumn{7}{|c|}{ Compound A1 } \\
\hline 0.0063 & 0.7942 & 0.5908 & 0.98 & 849.30 & 1.56 & 72.53 & 1.1037 \\
\hline 0.0125 & 0.7032 & 0.5560 & 1.05 & 860.93 & 1.58 & 72.51 & 0.9611 \\
\hline 0.0250 & 0.6361 & 0.5288 & 1.11 & 879.78 & 1.61 & 73.34 & 0.8737 \\
\hline 0.0500 & 0.6102 & 0.5179 & 1.14 & 925.07 & 1.70 & 76.92 & 0.8495 \\
\hline 0.1000 & 0.5092 & 0.4731 & 1.26 & 1050.97 & 1.93 & 85.49 & 0.6947 \\
\hline \multicolumn{7}{|c|}{ Compound A2 } & \\
\hline 0.0063 & 0.8636 & 0.6161 & 0.94 & 828.26 & 1.53 & 71.73 & 1.1689 \\
\hline 0.0125 & 0.7619 & 0.5799 & 1.01 & 852.72 & 1.57 & 72.78 & 1.0271 \\
\hline
\end{tabular}




\begin{tabular}{|l|l|l|l|l|l|l|l|}
\hline 0.0250 & 0.6945 & 0.5525 & 1.07 & 889.85 & 1.64 & 75.16 & 0.9455 \\
\hline 0.0500 & 0.6152 & 0.5200 & 1.14 & 974.78 & 1.79 & 81.22 & 0.8373 \\
\hline 0.1000 & 0.5247 & 0.4803 & 1.24 & 1146.37 & 2.10 & 93.81 & 0.6981 \\
\hline \multicolumn{7}{|c|}{ Compound A3 } \\
\hline 0.0063 & 0.7542 & 0.5757 & 1.02 & 834.24 & 1.53 & 71.02 & 0.9219 \\
\hline 0.0125 & 0.6994 & 0.5544 & 1.06 & 860.10 & 1.58 & 72.53 & 0.8803 \\
\hline 0.0250 & 0.6184 & 0.5213 & 1.13 & 905.60 & 1.66 & 75.24 & 0.7738 \\
\hline 0.0500 & 0.5625 & 0.4972 & 1.19 & 984.56 & 1.80 & 80.98 & 0.7032 \\
\hline 0.1000 & 0.5124 & 0.4746 & 1.25 & 1143.66 & 2.09 & 93.21 & 0.6459 \\
\hline
\end{tabular}

Table 3. Relaxation strength (r),Viscous relaxation time $(\tau)$, Isothermal compressibility $(\beta \mathrm{T})$, Isothermal expansion co-efficient $(\alpha)$, Internal pressure $(\pi \mathrm{i})$ and Free volume $(\mathrm{Vf})$, Solvation number (Sn) and Relative Association (RA) of 2,5-Disubstituted-1,3,4-Oxadiazole derivatives with Acetone at $303.15 \mathrm{~K}$.

\begin{tabular}{|c|c|c|c|c|c|c|c|c|}
\hline $\begin{array}{c}\text { Mole } \\
\text { fraction }\end{array}$ & $\mathrm{r}$ & $\tau \times 10^{12}$ & $\beta \mathrm{T} \times 10^{14}$ & $\alpha \times 10^{-4}$ & $\pi_{\mathrm{i}} \times 10^{-12}$ & $\mathrm{~V}_{\mathrm{f}} \times 10^{19}$ & $\mathrm{~S}_{\mathrm{n}} \times 10^{-2}$ & R.A \\
\hline $\mathrm{X}_{2}$ & & $\mathrm{Sec}$ & $\mathrm{m}^{2} \mathrm{~N}^{-1}$ & $\mathrm{~K}^{-1}$ & $\mathrm{~m}^{2} \mathrm{~N}^{-1}$ & $\mathrm{~m}^{3} \mathrm{~mol}^{-1}$ & & \\
\hline \multicolumn{7}{|c|}{ Compound A1 } \\
\hline 0.0063 & 0.3497 & 0.7222 & 1.1759 & 1.2242 & 3.1560 & 6.6948 & 3.4533 & 0.8002 \\
\hline 0.0125 & 0.2794 & 0.6620 & 1.0347 & 1.1857 & 3.4738 & 5.0558 & 2.4686 & 0.8017 \\
\hline 0.0250 & 0.2205 & 0.6259 & 0.9292 & 1.1542 & 3.7656 & 3.9019 & 1.5031 & 0.8086 \\
\hline 0.0500 & 0.1974 & 0.6175 & 0.8876 & 1.1411 & 3.8972 & 3.2146 & 0.8035 & 0.8148 \\
\hline 0.1000 & 0.0457 & 0.5506 & 0.7388 & 1.0899 & 4.4722 & 1.7461 & 0.5028 & 0.7978 \\
\hline \multicolumn{7}{|c|}{ Compound A2 } \\
\hline 0.0063 & 0.4113 & 0.7277 & 1.2720 & 1.2485 & 2.9754 & 8.1266 & 2.3691 & 0.8264 \\
\hline 0.0125 & 0.3432 & 0.6754 & 1.1228 & 1.2101 & 3.2674 & 6.0052 & 1.9725 & 0.8208 \\
\hline 0.0250 & 0.2865 & 0.6480 & 1.0139 & 1.1797 & 3.5272 & 4.5059 & 1.2701 & 0.8214 \\
\hline 0.0500 & 0.2018 & 0.6070 & 0.8957 & 1.1437 & 3.8707 & 2.9497 & 0.7934 & 0.8133 \\
\hline 0.1000 & 0.0717 & 0.5457 & 0.7619 & 1.0983 & 4.3700 & 1.5585 & 0.4873 & 0.7996 \\
\hline \multicolumn{7}{|c|}{ Compound A3 } \\
\hline 0.0063 & 0.3342 & 0.6104 & 1.1062 & 1.2057 & 3.3039 & 6.0956 & 4.1216 & 0.8198 \\
\hline 0.0125 & 0.2843 & 0.6043 & 1.0248 & 1.1828 & 3.4989 & 4.9462 & 2.4995 & 0.8125 \\
\hline 0.0250 & 0.1979 & 0.5623 & 0.9033 & 1.1461 & 3.8463 & 3.4886 & 1.5742 & 0.8046 \\
\hline 0.0500 & 0.1265 & 0.5333 & 0.8192 & 1.1184 & 4.1389 & 2.4370 & 0.8991 & 0.8007 \\
\hline 0.1000 & 0.0465 & 0.5117 & 0.7448 & 1.0921 & 4.4453 & 1.5010 & 0.4996 & 0.7936 \\
\hline
\end{tabular}

The internal pressure increases \& free volume decreases with increases in molar concentration indicate the association through hydrogen bonding. It shows the increasing magnitude of interaction between the 1,3,4-oxadiazole derivatives and acetone. The decrease in free volume shows that the strength of interaction decreases gradually with the increase in 
solute concentration. It represents that there is weak interaction ${ }^{28}$ between the solute and solvent molecules.

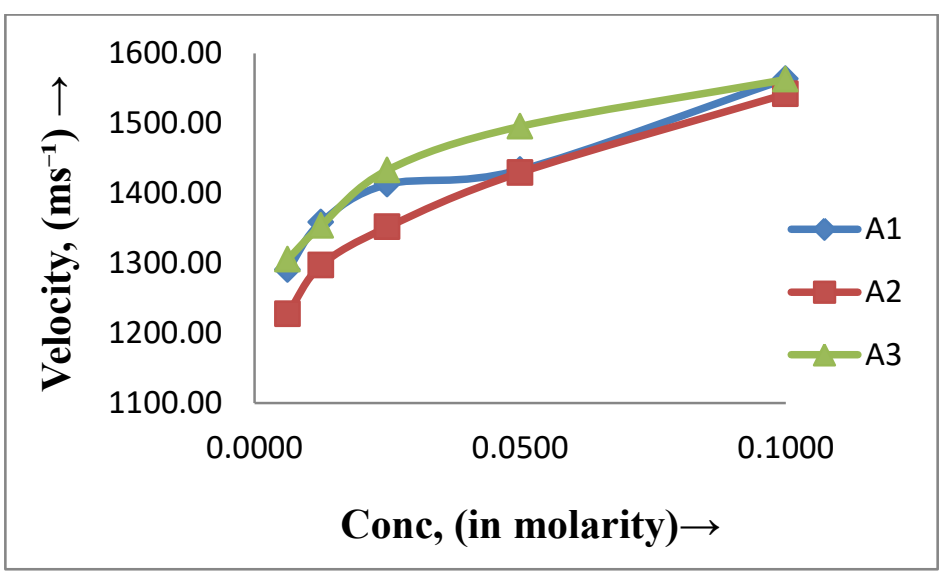

Fig. 1. Velocity Vs Concentration of AT1, AT2 and AT3 at 303.15 K.

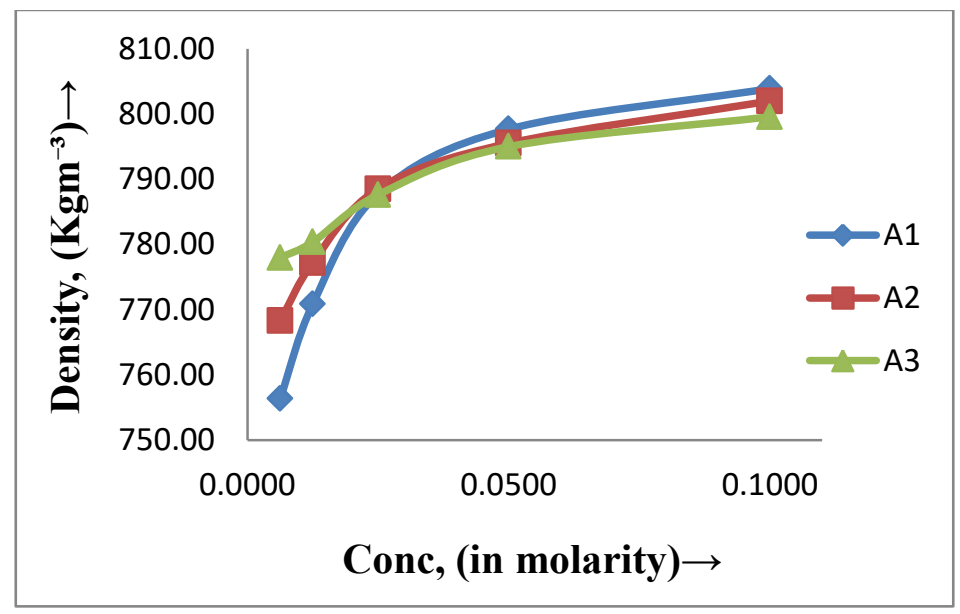

Fig. 2. Density Vs Concentration of A1, A2 and A3 at $303.15 \mathrm{~K}$.

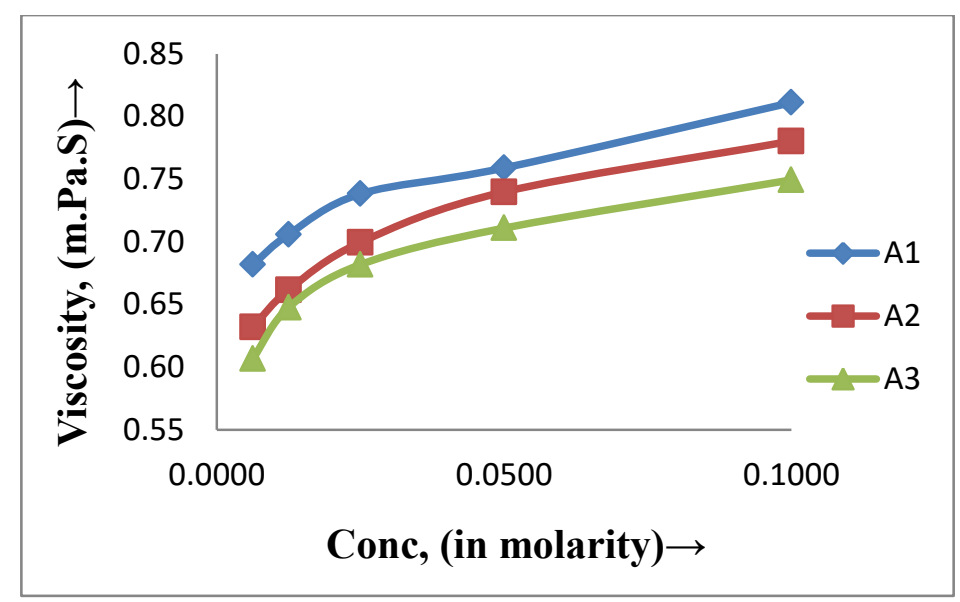

Fig. 3. Viscosity Vs Concentration of A1, A2 and A3 at $303.15 \mathrm{~K}$. 


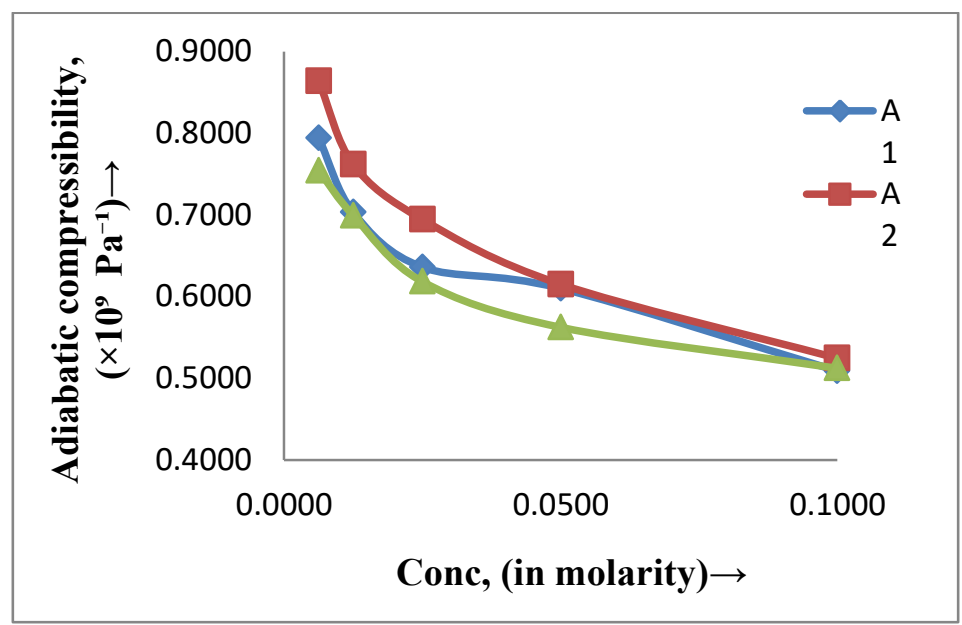

Fig. 4. Adiabatic compressibility Vs Concentration of A1, A2 and A3 at $303.15 \mathrm{~K}$.

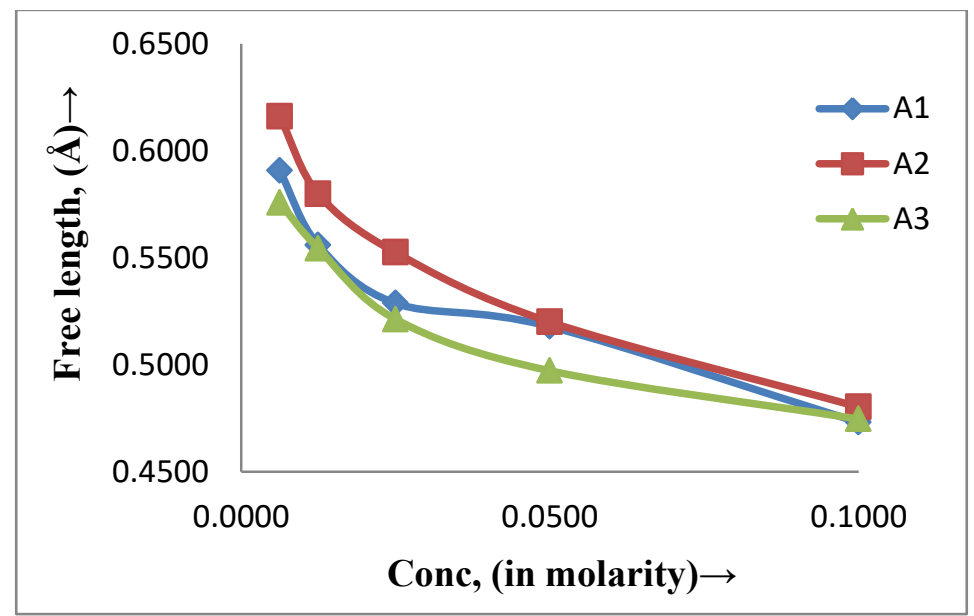

Fig. 5. Free length Vs Concentration of A1, AT2 and AT3 at $303.15 \mathrm{~K}$.

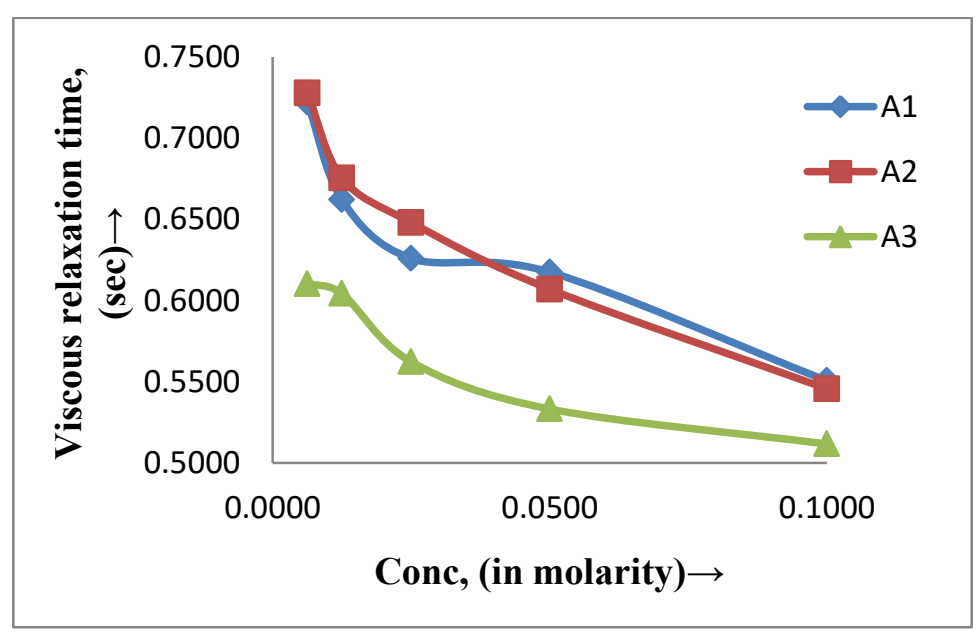

Fig. 6. Viscous relaxation time Vs Concentration of A1, A2 and A3 at $303.15 \mathrm{~K}$. 


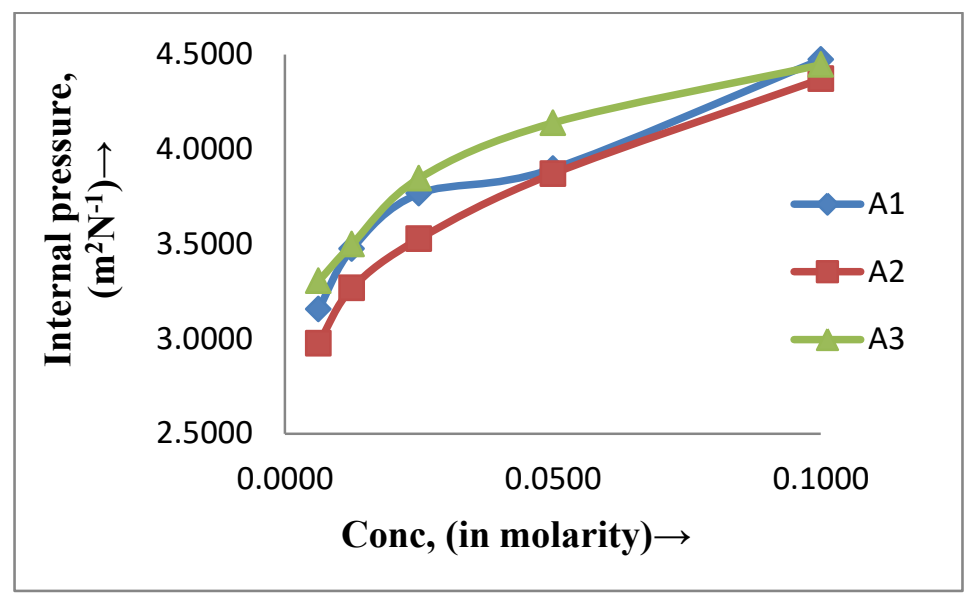

Fig. 7. Internal pressure Vs Concentration of A1, A2 and A3 at $303.15 \mathrm{~K}$.

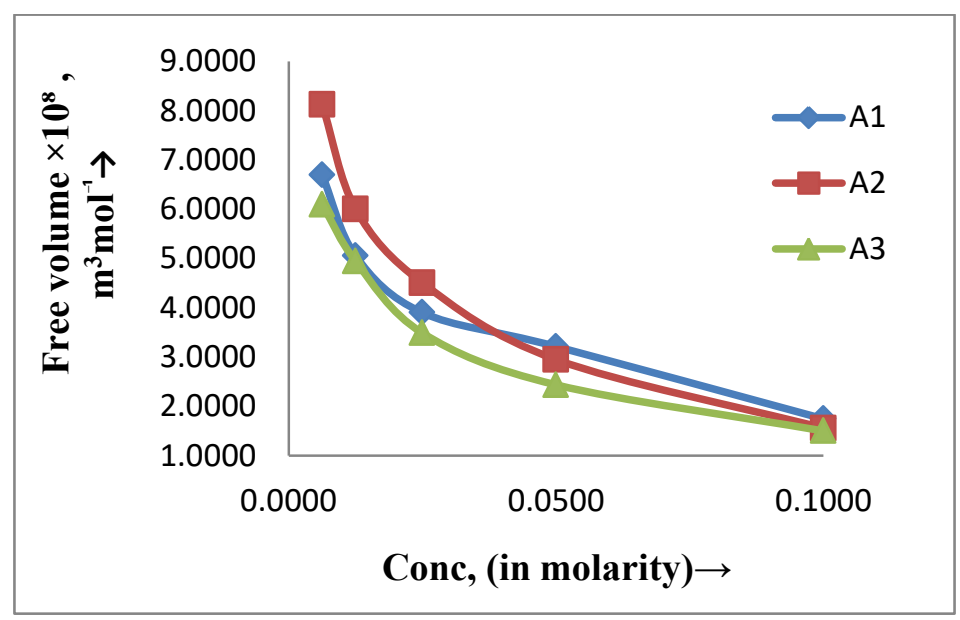

Fig. 8. Free volume Vs Concentration of A1, A2 and A3 at $303.15 \mathrm{~K}$.

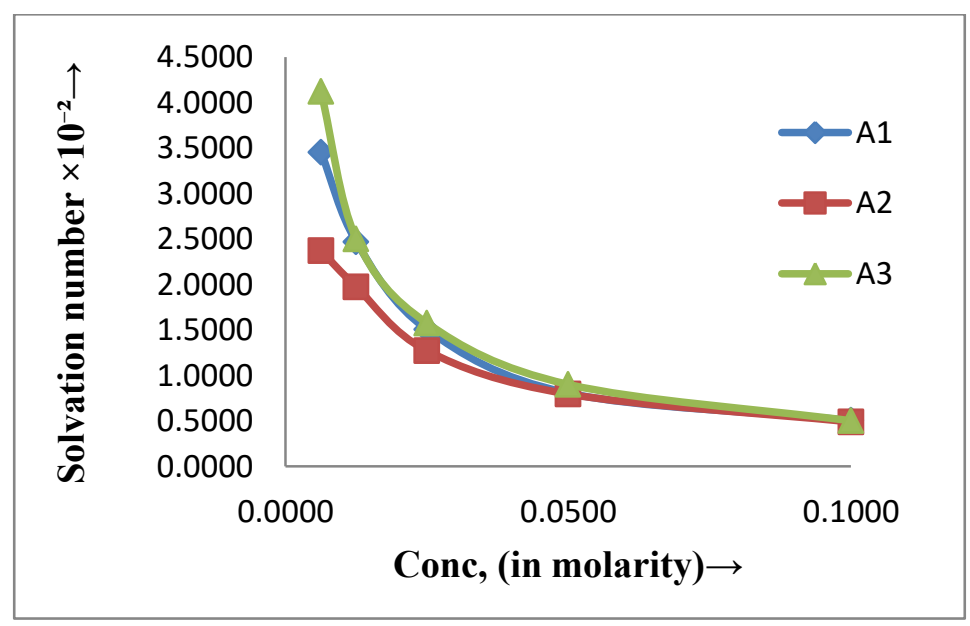

Fig. 9. Solvation number Vs Concentration of A1, A2 and A3 at $303.15 \mathrm{~K}$. 
The interactions occurring in different solutions can also be confirmed by the solvation number (Sn), which is measure of structure forming or structure breaking tendency of solute in a solution. Fig. 8 shows the variation of solvation number $(\mathrm{Sn})$ with molefractions for all the compounds in acetone. Sn values are found decrease with concentration of solute in acetone (shown in Table 3). Sn clearly represents the solvation of solute in solvent causes interactions giving rise to increase the solubility of solute ${ }^{29}$.

This weak association is further confirmed by low relative association value (RA), this is almost same for all compounds (Table 3). The decrease of relative association with concentration substantiate that the solvent structure breaks up.

\section{CONCLUSION}

All the computed acoustical parameters and their values point to the presence of specific molecular interaction in the liquid mixtures of 1-(5-amino-2-phenyl-1,3,4oxadiazole-3(2H)-yl) ethanone, 1-(5-amino-2-(3-(trifluoromethyl)phenyl)-1,3,4-oxadiazole$3(2 \mathrm{H})$-yl) ethanone, 1-(5-amino-2-(2,4-dimethoxyphenyl)-1,3,4-oxadiazole-3(2H)-yl) ethanone. Hence it is concluded that the association in these mixtures is the result of Hydrogen bonding between the molecule and acetone.

\section{References}

[1] Sen S. N., Acoustics: Waves \& Oscillations, Wiley Eastern Limited, (1990).

[2] Kannappan A. N., Palani R., Ind. J. Pure and Appl. Phys. (46A) 54 (2007).

[3] Vasantharani P., Kalaimagal P., Kannappan A. N., Asian J. applied Science. 2(1) (2009) 96.

[4] Rao G. V., Viswanatha Sarma A.Siva Rama Krishna J., Ind. J. Pure and Appl. Phys. 43 (2005) 345-354.

[5] Kannappan V., Xavier Jesu Raja S., Jaya Santhi R., Indian J. Pure Appl. Phys. 41 (2003) 690.

[6] Weissberger A., Technique of organic chemistry Vol.7 (2nd edn), Interscience New York, (1955).

[7] Edward I. Peters., Introduction to chemical principles (ch/4), 3rd Edu CCBS College Publishing (Philadelphia). 324 (1982).

[8] Tiwari V., Pandey J. D., Ind. J. pure appl physics. 18 (1980) 51.

[9] Jacobson B., Acta Chem. Scand. 6 (1952) 1485.

[10] Kincaid J. F., Eyring H., J. Chem. Phys. 6 (1938) 620.

[11] Subba Rao S., Gopalakrishanan R., J. Acoust. Soc. India. 7(1) (1975) 5.

[12] Rama Rao M., J. Chem. Phys. 9 (1941) 682.

[13] Rama Rao M., Indian J. Phys. 14 (1940) 109.

[14] Rama Rao M., Current Sciences 8 (1939) 510. 
[15] Singh D. P., Bhatil S. S., Acoustics Lett. 8(5) (1984) 84.

[16] Wada Y., J. Phys. Soc. Japan. 4 (1949) 280.

[17] Vigoureux P., Ultrasonics. Chapman and Hall Ltd., London (1952) 109.

[18] Willis F. H., J. Acoust. Soc. Am. 19 (1947) 242.

[19] Pandey J. D, Shukkla A. K, Neelima Tripathi, Dubey G. P., Pramana. 40 (1993) 81.

[20] Jong-Rim Bae, Journal of the Korean Physical Society 48(3) (2006) 490.

[21] Endo H., Bull Chem Soc Jpn. 46(4) (1973) 1106.

[22] Rita Mehra, Shilpi Vats, International Journal of Pharma and Bio Sciences 1(4) (2010) 523.

[23] Saneel K. Thakur, Shivani Chauhan, J. Chem. Pharm. Res. 3(2) (2011) 657.

[24] Kinsler L. E, Fray A. R., Fundamentals of Acoustica, Wisely Eastern, New Delhi, (1989).

[25] Bender J. M., Pecora, J. Phy. Chem. 90 (1986) 1700.

[26] Shanmuga Priya C., International J. of Advanced Sci. \& Tech. 18 (2010) 59.

[27] Aswale S. R., J. Chem. Pharm. Res 3(6) (2011) 233.

[28] Ubagaramary D., Neeraja P., International Refereed Journal of Engineering and Science (IRJES) 1(4) (2012) 54.

[29] Kannappan V., Vinayagam S. C., Indian J. of Pure and Appl. Phys. 45 (2007) 145.

[30] N. Santhi, P. Sabarathinam, G. Alamelumangai, J. Madhumitha, M. Emayavaramban, International Letters of Chemistry, Physics and Astronomy 5 (2012) 1-7.

[31] N. Santhi, P. L. Sabarathinam, G. Alamelumangai, J. Madhumitha, M. Emayavaramban, International Letters of Chemistry, Physics and Astronomy 5 (2012) 59-71.

[32] N. Santhi, P. L. Sabarathinam, J. Madhumitha, G. Alamelumangai, M. Emayavaramban, International Letters of Chemistry, Physics and Astronomy 2 (2013) 18-35.

[33] M. Durga Bhavani, A. Ratnakar, Ch. Kavith, International Letters of Chemistry, Physics and Astronomy 5 (2013) 1-6.

[34] S. S. J. Srinivas, B. Tulasi Koteswari Bai, K. Babu Rao, K. Narendra, M. Sarath Babu, International Letters of Chemistry, Physics and Astronomy 10(2) (2013) 151-158.

[35] C. H. Srinivasu, K. Anil Kumar, S. K. Fakruddin, K. Narendra, T. Anjaneyulu, International Letters of Chemistry, Physics and Astronomy 13 (2013) 1-7. 